بررسى پيايدارى عملكرد ارقام لوبيا به روشهاى مختلف يكمتغيره و جندمتغيره

محمد ربيعى "و محمود خدامباشى

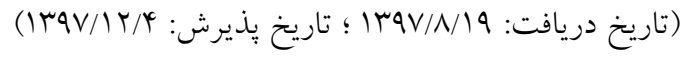

حكيده

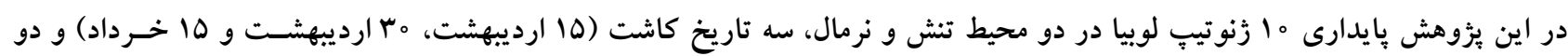

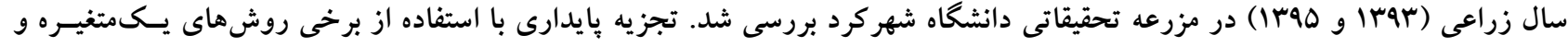

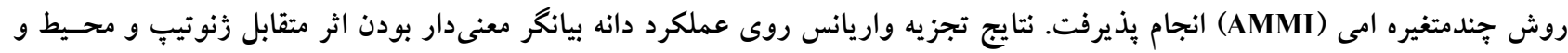

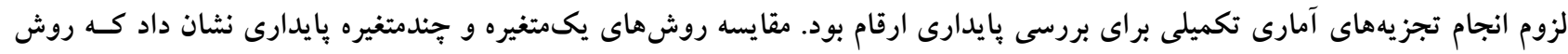

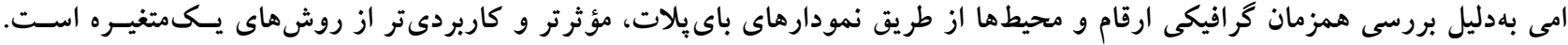

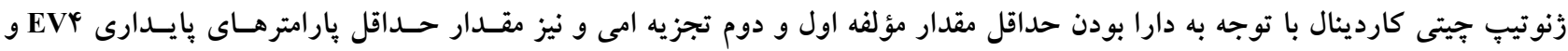
SIPCF

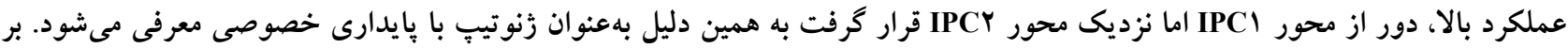

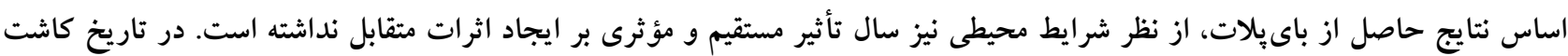

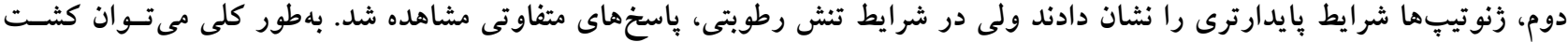

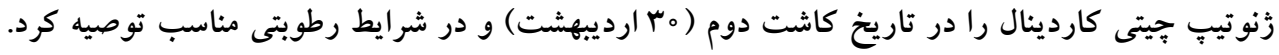

وازههاى كليدى: امى، باى يلات، تاريخ كاشت، تنش رطوبتى، بايدارى 
محيط وجود دارد كه شامل روشهاى يكمتغيـره و جنــمتغيره

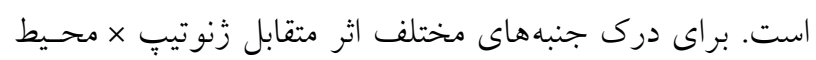

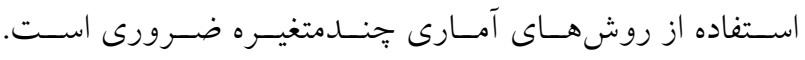

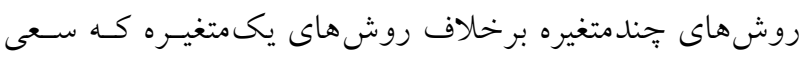

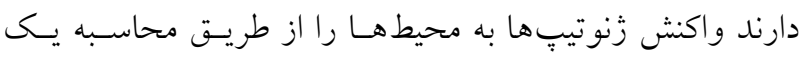

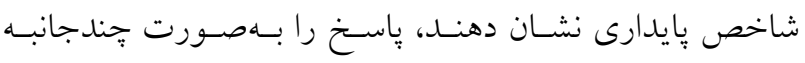

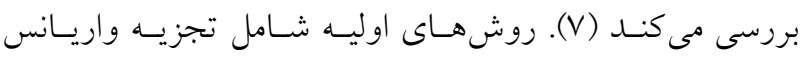

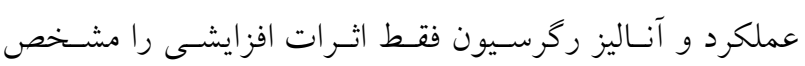

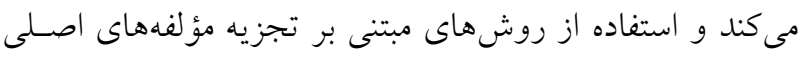

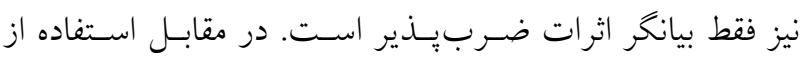
روشهاى جندمتغيره مثل روش AMMI بهطور همزمان اثـرات

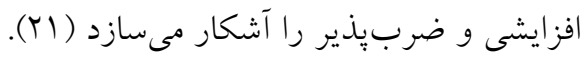

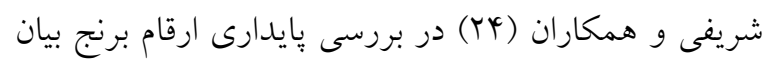

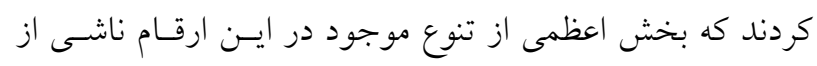

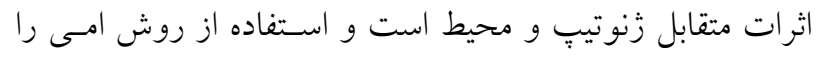

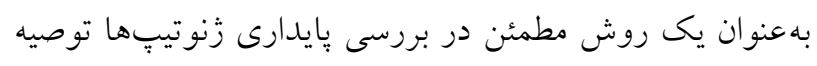

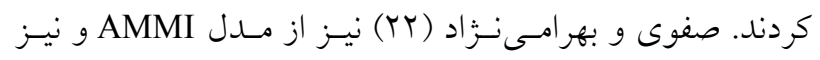

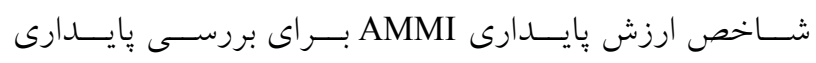

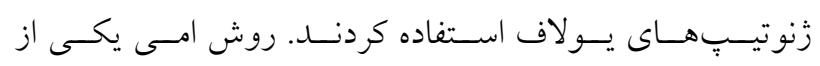

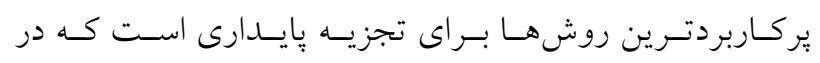

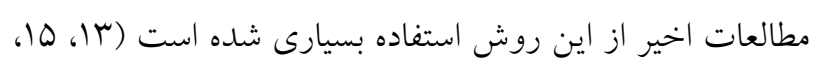

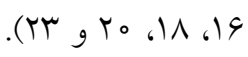
بررسى بايدارى زنوتيبها در شرايط تنش و نرمال بهمنظـور

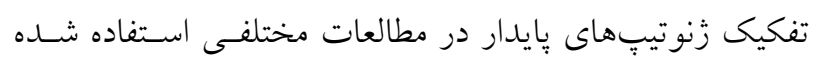

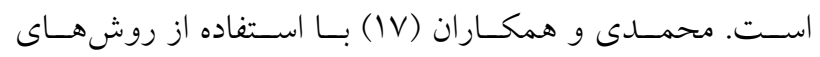

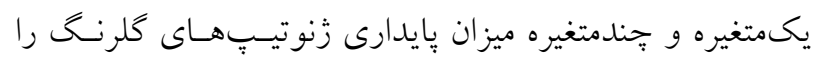

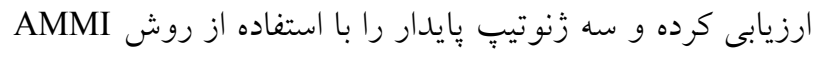

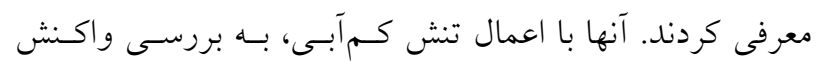

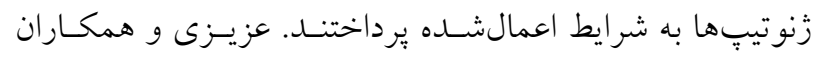

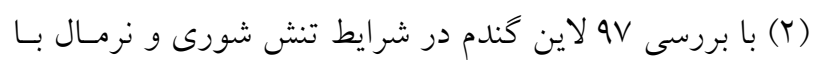

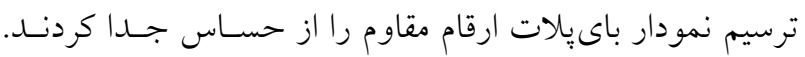

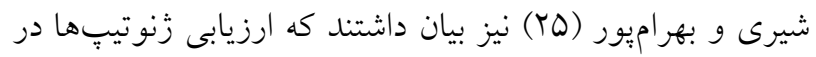

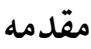

لوبيـا (Phaseolus vulgaris L.) مهـمتــــين كيـاه از خـانواده حبوبات است كه بـهـــــوان يـك كيـاه مـــل در مطالعـات ايسن

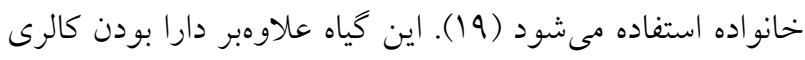

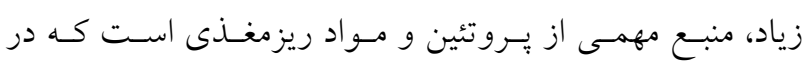

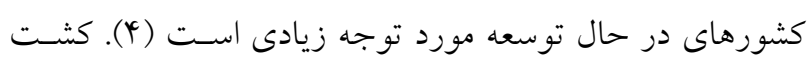

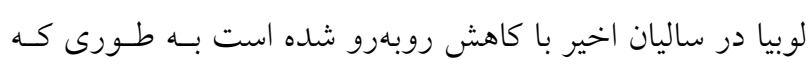

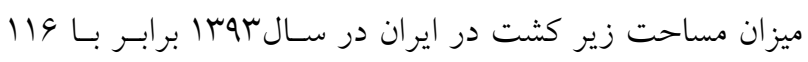

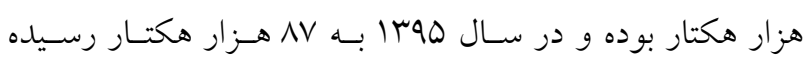

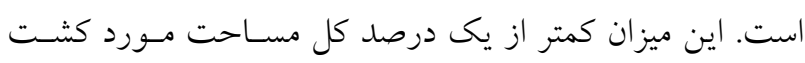

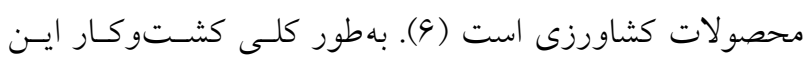

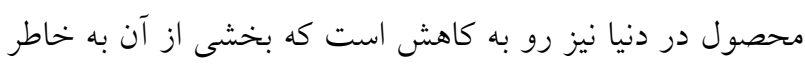

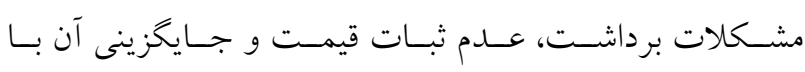

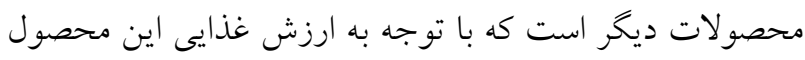
راهكارهاى جدى و مؤثرى را بـراى حفـظ ايسن كيـاه در برنامـهـ

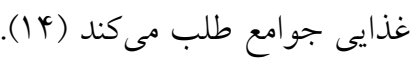

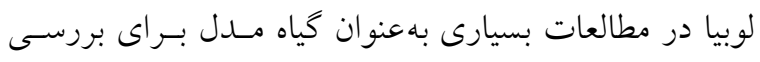
ساز كارى حبوبات به شرايط محيطى اسـفاده شـــه اسـت (†). بيب و همكاران (Y) با بررسى گونهاى مختلف لوبيـا در تسنش

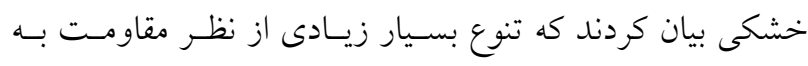

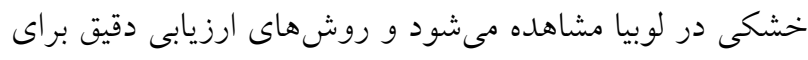

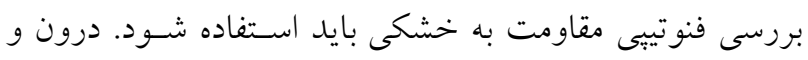

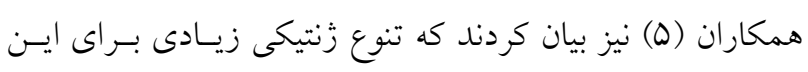

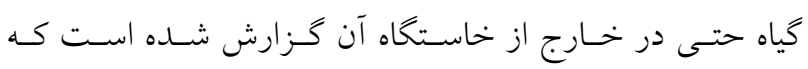

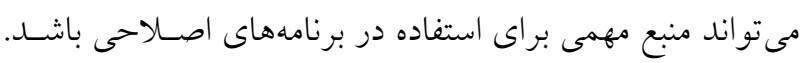

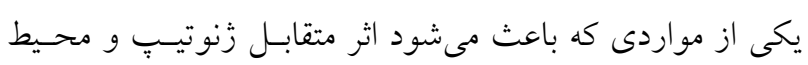

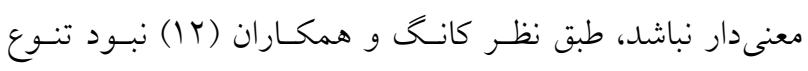

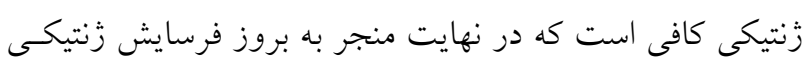

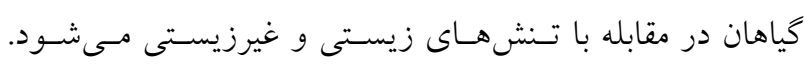

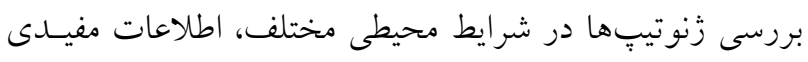

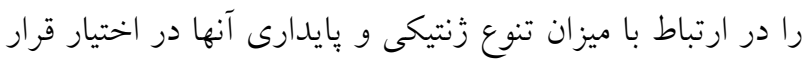

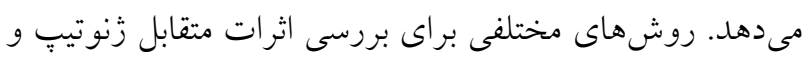


تهيه زمين معادل 100 كيلو گرم در هكتار كود فسفات آمونيوم،

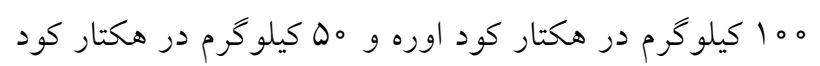

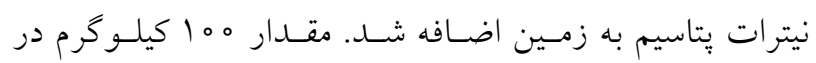

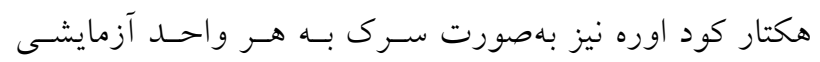

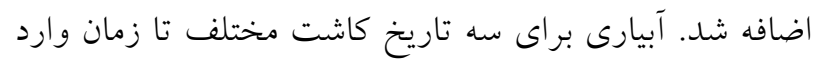

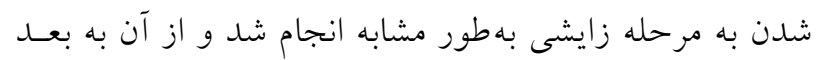

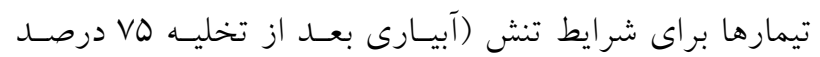

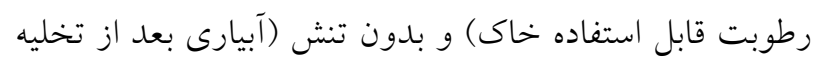

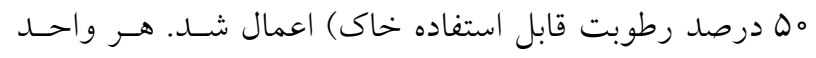

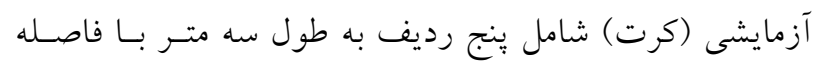

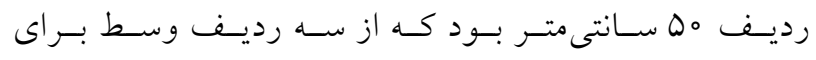

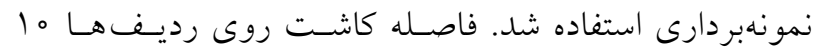

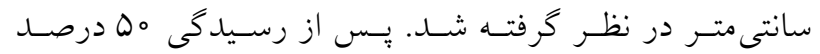

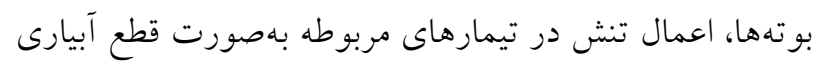

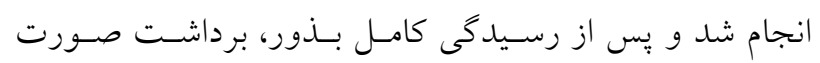

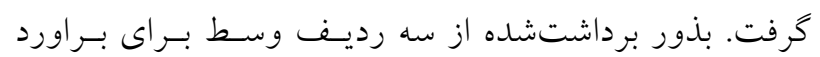

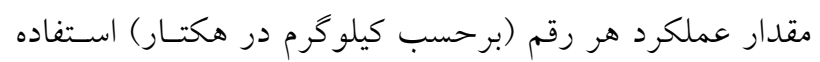

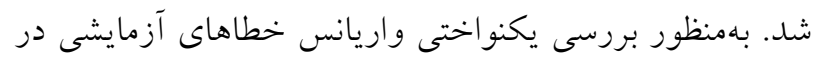

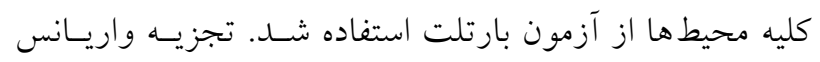

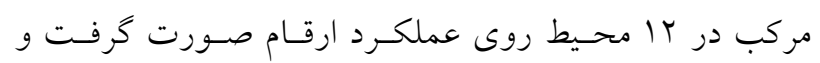

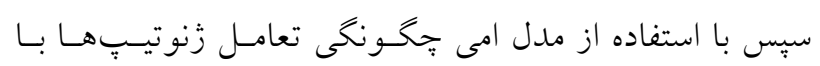

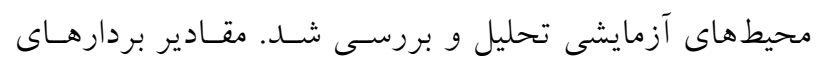

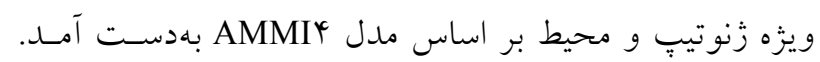

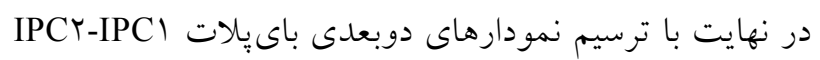

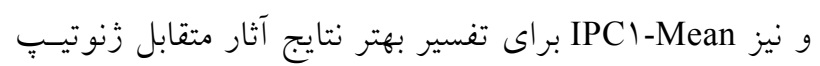

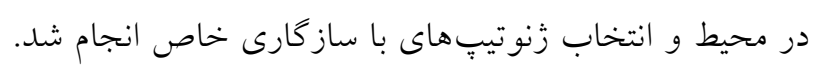

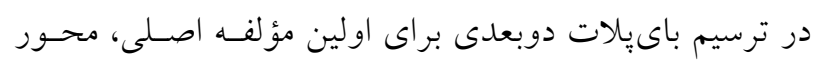

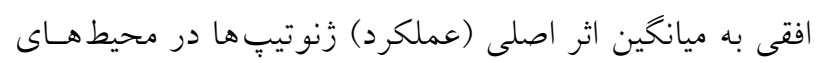

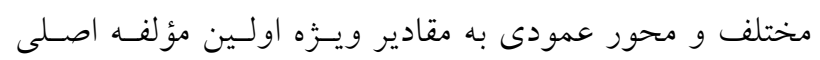

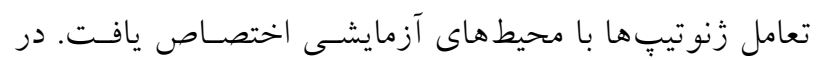

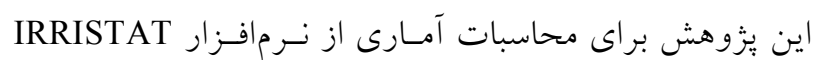

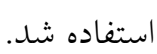

شــرايط مختلــف تــش آبسى، مسى توانسـد در مشـخص كـردن

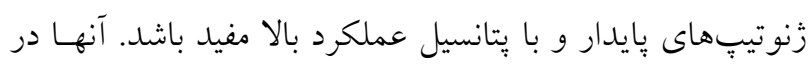
بررسى هفت هيبريد ذرت نشان دادند كه با توجـه بـه معنسى دار

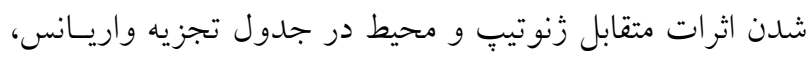

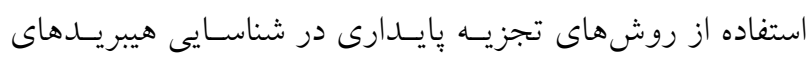

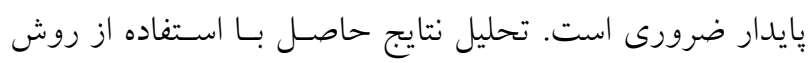

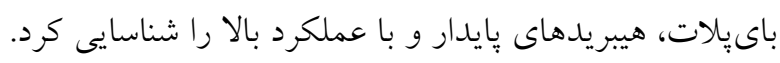

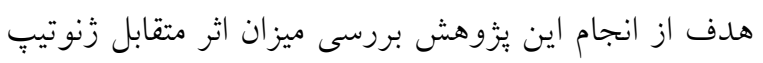

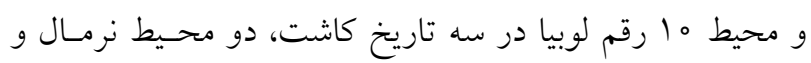

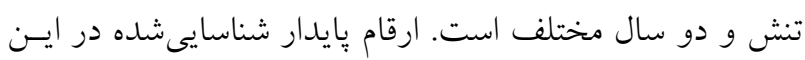

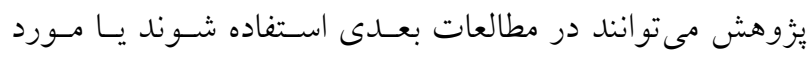
كشت كار قرار كيرند.

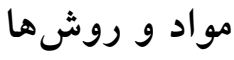

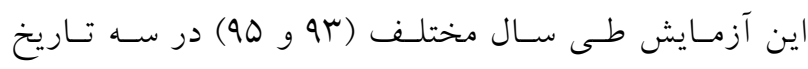

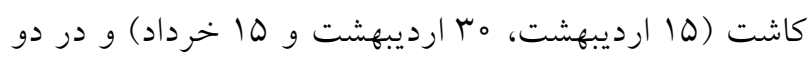
محيط تنش (كمآبيارى) و نرمال در مزرعه تحقيقاتى دانشگاه

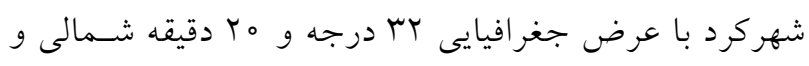

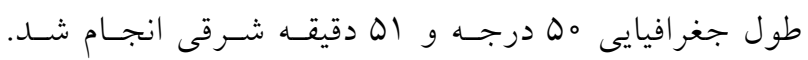

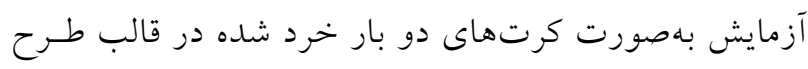

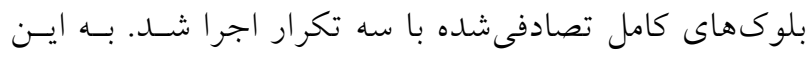
ترتيب كه تاريخ كاشت به عنوان عامل اصلى، آبيارى به عنوان تصنان

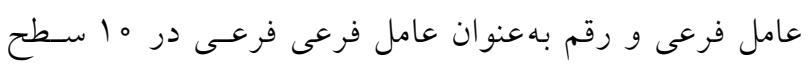
در نظر كرفته شد.

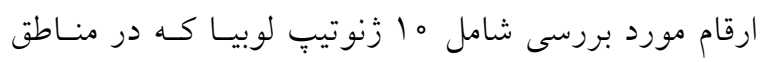

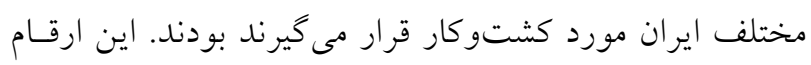

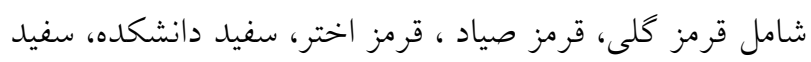

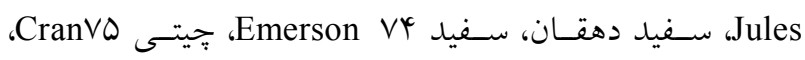
جيتسى كاردينـال و جيتسى Mich MP هسـتند. اسـامى ارقـام

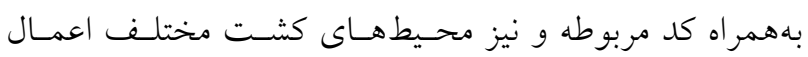

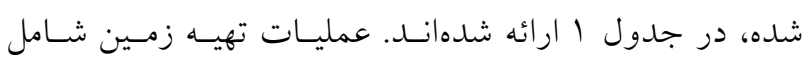
شخم و ديسكزنى، قبل از كاشت صورت كرفـت. در هنگــام 
جدول ا. زنوتيبٍها و محيطهاى به كار رفته در اين آزمايش و كدهاى مربوط كه در جدولها و شكلها استفاده شدهاند

\begin{tabular}{|c|c|c|c|}
\hline كد & محيط & كد & نام زنوتيب \\
\hline fnl & تاريخ كاشت اول-محيط بدون تنش- سال اول & $\mathrm{Cl}$ & 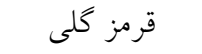 \\
\hline fs 1 & تاريخ كاشت اول-محيط تنش- سال اول & $\mathrm{Cr}$ & قرمز صياد \\
\hline sn 1 & تاريخ كاشت دوم-محيط بدون تنش - سال اول & $\mathrm{Cr}$ & 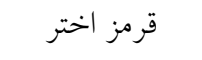 \\
\hline ss 1 & تاريخ كاشت دوم- محيط تنش - سال اول & $\mathrm{Cr}^{\mathrm{r}}$ & سفيد دانشكده \\
\hline $\operatorname{tn} 1$ & تاريخ كاشت سوم- محيط بدون تنش - سال اول & $\mathrm{C} \otimes$ & سفيد Jules \\
\hline ts 1 & تاريخ كاشت سوم - محيط تنش - سال اول & $\mathrm{C} 9$ & سفيد دهقان \\
\hline fnr & تاريخ كاشت اول- محيط بدون تنش-سال دوم & $\mathrm{CV}$ & سفيد Emerson \\
\hline fs $\mathrm{r}$ & تاريخ كاشت اول-محيط تنش- سال دوم & $\mathrm{C} \wedge$ & 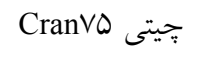 \\
\hline sn $r$ & تاريخ كاشت دوم- محيط بدون تنش - سال دوم & $\mathrm{Ca}$ & جيتى كاردينال \\
\hline ss & تاريخ كاشت دوم - محيط تنش - سال دوم & $\mathrm{Cl} \circ$ & Mich MP جيتى \\
\hline $\operatorname{tn} r$ & تاريخ كاشت سوم - محيط بدون تنش - سال دوم & & \\
\hline ts $Y$ & تاريخ كاشت سوم - محيط تنش - سال دوم & & \\
\hline
\end{tabular}

كردند و اثرات اين جهار مؤلفه در آزمون F معنى دار بـود، مــل AMMIY براى اين تجزيه انتخاب شد.

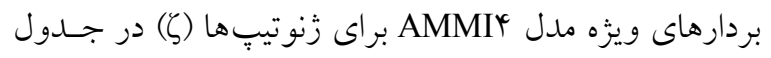

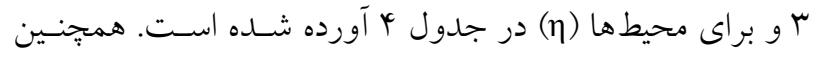
مقادير منفرد و مقادير مؤلفههاى اصلى زنوتيبهــا و محسيطهـا در جداول ه و 9 ارائه شده است. اين مؤلفهها از حاصل ضرب جـذر مقدار منفرد در بردارهاى ويزه محيطى و زنوتييى بهدست مى آينـد و در شناسايى زنوتيِّهاى بايدار استفاده مىشوند. نمودار بر اكنش زنوتيبٍ ها و محيطها بر مبناى اولـين مؤلفـه

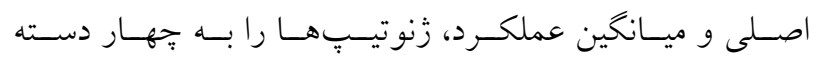
تقسيمبندى كرد (شكل (1). محور افقى اين نمودار نشـاندهنــده است كه ناحيه فتــدان اثــر متقابـل را نشـان مسىدهـد. IPCl=0

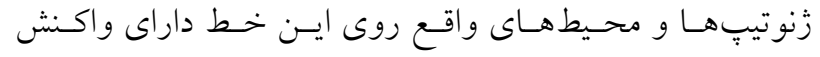
مشابهى از نظر اثر متقابل هستند. زنوتيڤها و محيطهايى كه اثر متقابل بالايى را نشان مى دهند، داراى مقادير بزرگ بـراى اولـين مؤلفه هستند؛ درحالى كه زنوتيِّها و محيطهـاى دار ای مقـادير نزديك به صفر براى اولين مؤلفه اصلى داراى اثر متقابـل يـايين هستند. زنو تيبّها و محيطهـايى كـه علامـت مشـابهى را بـراى
نتايج و بحث

ابتدا براى آزمون همخنى واريانس خطاى آزمايشى محسيطهـاى

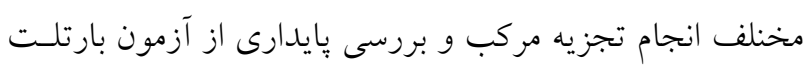
استفاده شد. مقدار كاىاسكور محاسبه شده در اين آزمون برابـر با ا ا بود كه از مقدار كاىاسكور جدول با درجه آزادى Iل و در سطح معنى دار يك درصد (YY/V) كوجنىتر بـود. بـهـ همسين

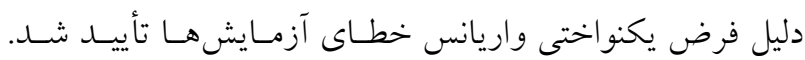
نتايج تجزيه مركب آزمايشها در جدول ب ارائه شده اسـت كـه. بيانكر معنى دار بودن اثر متقابل زنوتيبٍ و محيط اسـت. بـه ايسن دليل بررسى پياسخ زنوتيٌها در شرايط محيطهاى مختلف لازم است و تجزيه يايدارى مىتواند كمى شايانى در شناسايى ارقام يايدار داشته باشد. همانطور كه در اين جدول مشاهده مىشود، ميزان تعامل زنوتيبٌ و محيط به جهار جزء AMMI و يك جزء نويز (باقيمانده) تفكيك شده است. اخر بيشترين ميـزان مجمـوع

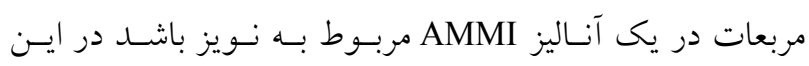
صورت انجام آناليز امى و بررسى نتايج آن درست نيست (11). با توجه به اينكه جهار مؤلفه اول در تجزيه امسى در مجمـوع 919 درصد از مجموع مربعات اثرمتقابل زنوتيـٍ × محسيط را تبيسين 


\begin{tabular}{|c|c|c|c|}
\hline $\mathrm{F}$ & ميانگين مربعات & درجه أزادى & منبع تغييرات \\
\hline \multirow[t]{2}{*}{$r / \mu^{*}$} & YGY/4* & 11 & محيط \\
\hline & $110 / 9$ & TY & بلوك درون محيط \\
\hline$\varphi / T^{* *}$ & $90 / 1^{* *}$ & 9 & زَنوتيب \\
\hline $1 / \wedge^{* *}$ & $\varphi \circ / \wedge^{* *}$ & 99 & زنوتيب × محيط \\
\hline$r / \mathcal{G}^{* * *}$ & $\Delta 9 / \mu^{* *}$ & 19 & AMMI I \\
\hline$T / 90^{* *}$ & $\Delta V / \wedge^{* *}$ & IV & AMMI II \\
\hline$Y / \mathcal{A} Y^{* *}$ & $\Delta r / q^{* *}$ & 10 & AMMI III \\
\hline Y/GY"** & $\Delta \Lambda / \mu^{* * *}$ & ir & AMMI IV \\
\hline \multirow[t]{3}{*}{$\circ / 4 V^{* *}$} & $10 / 0 \mathrm{~ns}$ & ro & ن نويز \\
\hline & $T Y / T$ & Yl9 & خطا \\
\hline & & $T Y / T$ & ضريب تغييرات \\
\hline
\end{tabular}

ns * و ** بهترتيب بيانگر معنى دارنبودن و معنى دار بودن در سطح معنى دار ينج درصد و يك درصد است.

جدول س. بردارهاى ويزٔه زنوتييى اثر متقابل زنوتيب × محيط براى مدل AMMI

\begin{tabular}{|c|c|c|c|c|}
\hline$\zeta_{\psi}$ & $\zeta_{r}$ & $\zeta_{Y}$ & $\zeta_{1}$ & زَنوتيبِ \\
\hline $0 / 04$ & O/YY & $0 / 11$ & $-0 / 0 \mu$ & $\mathrm{Cl}$ \\
\hline $0-0 / Y 1$ & $0 / 14$ & $-0 / 0{ }^{r}$ & - & $\mathrm{Cr}$ \\
\hline$-0 / 10$ & ० & $-0 / 0 Y$ & $\circ / \circ V$ & $\mathrm{Cr}$ \\
\hline $0 / 04$ & $-\circ / \circ \wedge$ & $-o / / 4$ & $\circ / 10$ & $\mathrm{Cr}^{\mathrm{r}}$ \\
\hline$-0 / 04$ & $-0 / 04$ & $-0 / 04$ & ०/०Y & $\mathrm{Co}$ \\
\hline$-0 / T \varphi$ & $\circ / \circ \wedge$ & $0 / 04$ & $-0 / 0 Y$ & C4 \\
\hline $0 / 04$ & $0 / 14$ & $-0 / 0 \psi^{\varphi}$ & $-0 / 0 Y$ & $\mathrm{Cr}$ \\
\hline $0 / \mu q$ & $-\circ / \circ V$ & $0 / Y 1$ & $\circ / \%$ & $\mathrm{C} \wedge$ \\
\hline$\circ / \circ V$ & $0 / 0 \mu$ & $0 / 04$ & $-0 / 0 Y$ & $\mathrm{Ca}$ \\
\hline$\circ / \mu_{0}$ & $-0 / 04$ & ०/० & ०/० & $\mathrm{Cl}$ 。 \\
\hline
\end{tabular}

جدول fا. بردارهاى ويزٔه محيطى اثرمتقابل زنوتيب × محيط براى مدل AMMIY

\begin{tabular}{|c|c|c|c|c|}
\hline \multicolumn{4}{|c|}{ بردارهاى ويزٔه محيطى } & \multirow{2}{*}{ محيط } \\
\hline$\eta_{*}$ & $\eta_{r}$ & $\eta_{r}$ & $\eta_{1}$ & \\
\hline$-0 / 04$ & $-0 / 0 \mathrm{~V}$ & $0-0 / 0 r$ & $-0 / 1 \wedge$ & fnl \\
\hline$-0 / T V$ & $\circ / \circ \Delta$ & $-0 / 0 \wedge$ & $-\circ / 0 r$ & fs 1 \\
\hline$-0 / Y \wedge$ & $\circ \% \mathrm{~V}$ & $-0 / 09$ & $0 / 09$ & snl \\
\hline$-0 / 10$ & $-0 / 10$ & $\circ / \wedge$ & $-\circ / \circ \mathrm{V}$ & ss 1 \\
\hline$-0 / 04$ & . & $-0 / 0 r$ & $-0 / 10$ & $\operatorname{tn} 1$ \\
\hline$\circ / \wedge$ & $-0 / 19$ & $-0 / 0 r$ & $-0 / I V$ & ts 1 \\
\hline$-0 / / 4$ & $\circ / \Lambda$ & $\circ / \circ \circ 0$ & $-0 / T 4$ & fn $r$ \\
\hline $0 / Y 1$ & $-0 / 0 \varphi^{c}$ & $0 / 49$ &.$/ \Delta \Lambda$ & fs $r$ \\
\hline $0 / 41$ & &.$/ 11$ & $-0 / Y r$ & sn $r$ \\
\hline$\circ / \circ \wedge$ & $-0 / 0 V$ & $0 / 09$ & $0 / 14$ & ss $r$ \\
\hline$-0 / 44$ & $-0 / 01$ & $\circ / \circ \circ \Delta$ & $0 / T^{\prime}$ & $\operatorname{tn} r$ \\
\hline $0 / T 9$ & $-0 / 0 \psi^{k}$ & $-0 / 004$ & $0 / T V$ & ts $r$ \\
\hline
\end{tabular}


جدول ه. مقادير منفرد و مقادير مؤلفهاى اصلى اثرات متقابل در مدل AMMIY براى زنوتيبها

\begin{tabular}{|c|c|c|c|c|}
\hline \multicolumn{4}{|c|}{ مؤلفههاى اصلى اثرات متقابل } & \multirow{2}{*}{ 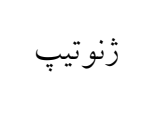 } \\
\hline $\mathrm{IPC}_{4}$ & $\mathrm{IPC}_{r}$ & $\mathrm{IPC}_{r}$ & IPC, & \\
\hline $0 / 1 Y$ & $0 / 19$ & $0 / 49$ & $-0 / 19$ & $\mathrm{Cl}$ \\
\hline$-\circ / \Delta \mu$ & $\circ / 0 \wedge$ & $-0 / 19$ & $-0 / I V$ & Cr \\
\hline$-\circ / \mu V$ & O/T & $-0 / 10$ & $\circ / \Lambda$ & $\mathrm{Cr}$ \\
\hline o/ K & - & $-0 / 91$ &.$/ D Y$ & $\mathrm{Cl}^{\boldsymbol{Y}}$ \\
\hline$-0 / 19$ & $-0 / 1 \wedge$ & $-0 / 19$ & $\circ / 14$ & $\mathrm{C} \omega$ \\
\hline$-0 / 94$ & سח/ם &.$/ 19$ & $-0 / 1 Y$ & C4 \\
\hline $0 / 10$ & $\circ / \Delta \wedge$ & $-0 / 19$ & $-0 / 1 Y$ & $\mathrm{CV}$ \\
\hline $0 / 99$ & $-0 / T V$ & ०/AV & $\circ / \wedge$ & $\mathrm{CA}$ \\
\hline$\circ / \wedge$ & $0 / 1 T$ &.$/ 19$ & $-0 / / 4$ & $\mathrm{C} 9$ \\
\hline$\circ / \mathrm{V}$ & $-0 / T \Delta$ & $\circ / 10$ & $\circ / 10$ & $\mathrm{Cl} \circ$ \\
\hline $9 / 4$ & $10 / 1 \circ$ & $I V / \Gamma_{\circ}$ & $r V / \Lambda \Lambda$ & مقدار منفرد \\
\hline
\end{tabular}

جدول 9. مقادير منفرد و مقادير مؤلفههاى اصلى اثرات متقابل در مدل AMMIF براى محيطها

\begin{tabular}{|c|c|c|c|c|}
\hline \multicolumn{4}{|c|}{ مؤلفههاى اصلى اثرات متقابل } & \multirow{2}{*}{ محيط } \\
\hline $\mathrm{IPC}_{4}$ & $\mathrm{IPC}_{r}$ & $\mathrm{IPC}_{r}$ & $\mathrm{IPC}_{1}$ & \\
\hline$-0 / 10$ & $-0 / Y \wedge$ & $-0 / / 4$ & $-0 / 90$ & fnl \\
\hline$-0 / 9 \Lambda$ & $0 / T \mu$ & س & $-0 / 19$ & fs I \\
\hline$-o / V I$ & $0 / M 1$ & $-\circ / \Gamma \wedge$ & $0 / 49$ & sn 1 \\
\hline$-\circ / \mu \Lambda$ & $-0 / 4 \circ$ & $0 / T_{4}$ & -0/4G & ss 1 \\
\hline$-0 / I V$ & $0 / 1 Y$ & $-0 / 1 \mu$ & $-\circ / V \wedge$ & $\operatorname{tn} 1$ \\
\hline $0 / T 1$ & $-0 / 94$ & $-0 / 1 \mu$ & $-0 / 19$ & ts 1 \\
\hline$-0 / T V$ & - $/ Q Y$ & $0 / 1 Y$ & $-0 / N Y$ & fnr \\
\hline$-0 / 09$ & $-0 / \mu_{4}$ & - & $-0 / 09$ & fs $r$ \\
\hline$-0 / T G$ & $-\circ / \mu V$ & $-0 / T \Delta$ & $0 / T \mu$ & snr \\
\hline - $/ Q Y$ & $-0 / 1 Y$ & $-o / Y Y$ & $-0 / 49$ & SST \\
\hline$-0 /{ }^{4}$ & $0 / 49$ & $0 / 49$ &.$/ 4 Q$ & $\operatorname{tn} r$ \\
\hline$\circ / T \mu$ & $-0 / Y \wedge$ & $-0 / T V$ & $-0 / 90$ & ts $r$ \\
\hline $9 / 4$ & $10 / \Lambda_{0}$ & IV/r。 & $r V / \Lambda \Lambda$ & مقدار منفرد \\
\hline
\end{tabular}

محيطهاى تنش در يك سمت محسور IPC قـرار كرفتـهانـد كـه

نشاندهنده اين است كه واكـشش اثـر متقابـل مشـابه و مثبتى را

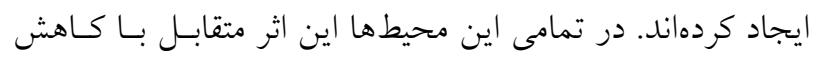

$$
\text { ميز ان عملكرد همراه بوده است. }
$$

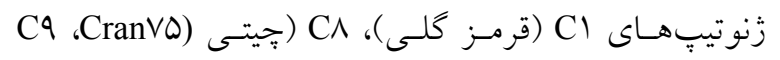

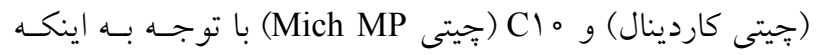
نزديك محور ال قرار گرفته و متوسط عملكرد بالاتر از حسـ ميانگين دارند، زنوتيبٍهاى داراى ساز گارى عمومى هستند.
مقادير IPC دارند، آثار متقابل مثبت را ايجاد مى كنند، در حالى كه تركيب مقادير IPCl با علامتهاى مختلف، اثر متقابل منفى سي را بهوجود مى آورد. تمامى محيطهاى تنش، متوسط عملكردى كمتر از ميـانخين كل نشان دادند و باعث بروز كمترين اثرات متقابل نيز شـــهانـد.

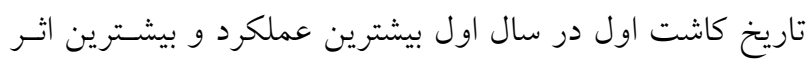

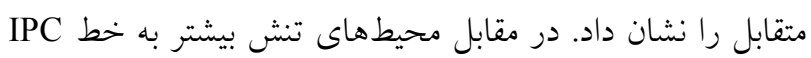

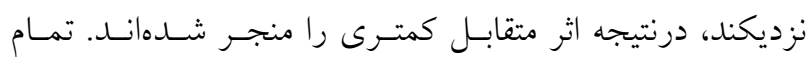




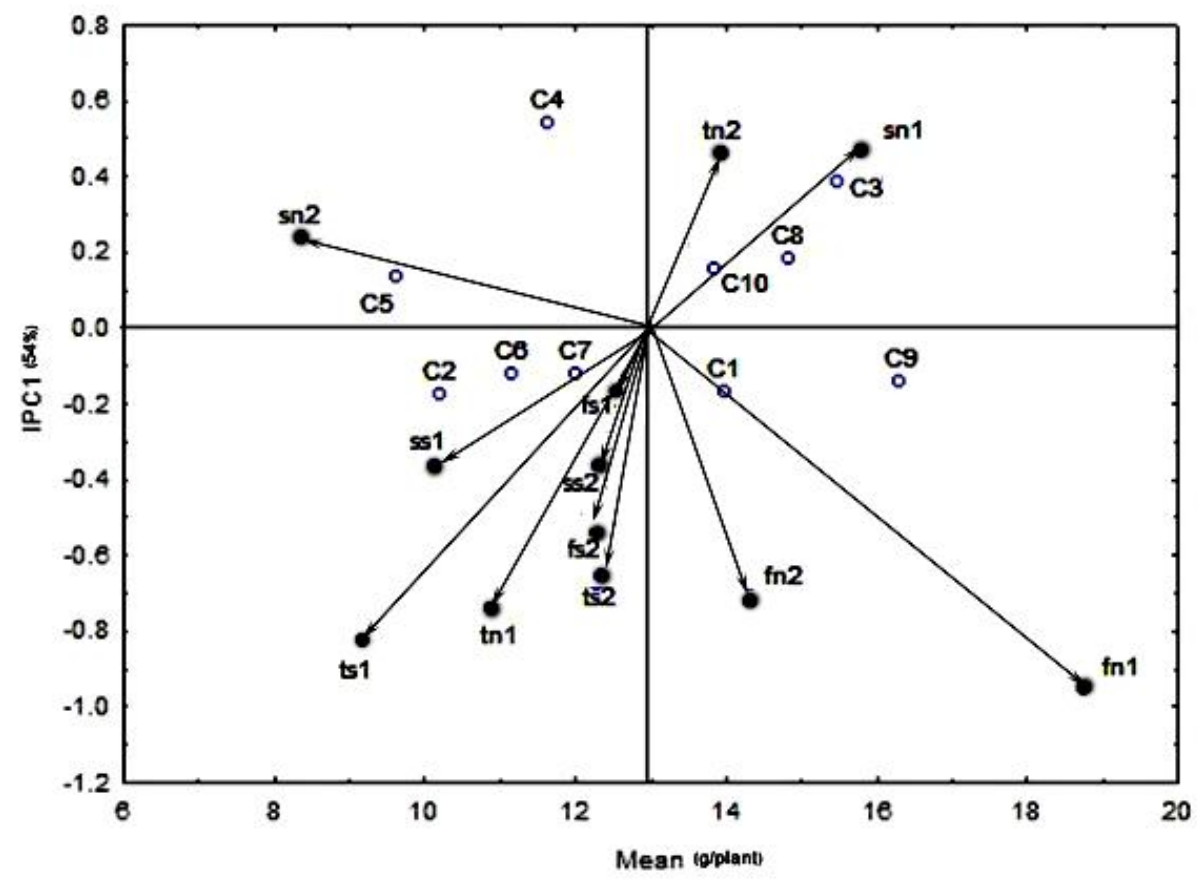

شكل ا. براكنش زنوتيبها و محيطها بر اساس ميانخين عملكرد و مقادير مربوط به مؤلفه اول تجزيه AMMI

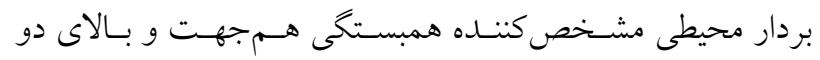

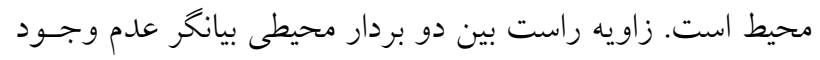

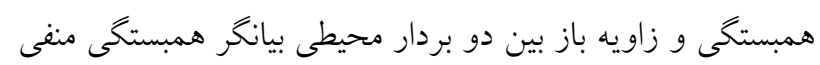
دو محيط از لحاظ ايجاد اثر متقابل است. ونان.

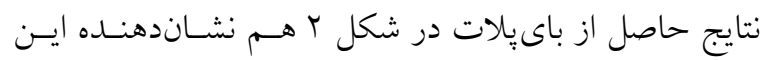

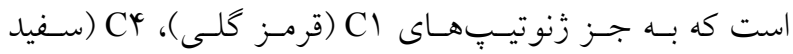

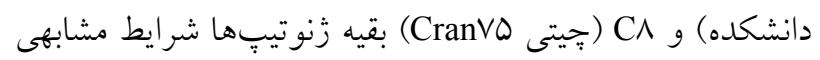

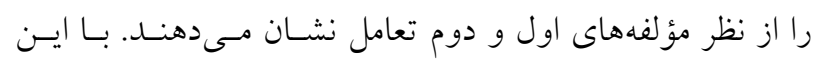

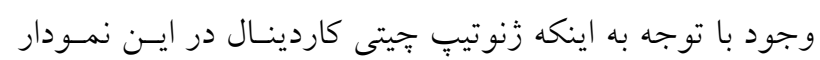

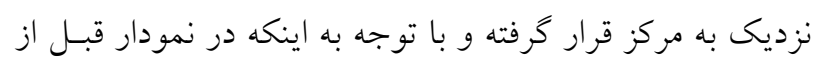
نظر ميزان متوسـط عملكـــد در تمـامى محسيطهـا داراى مقــدار

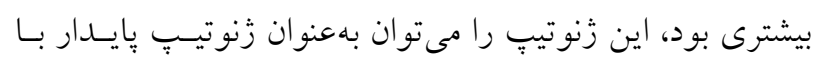

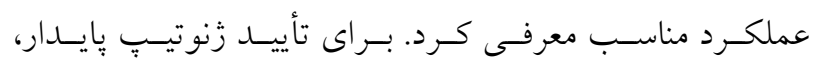

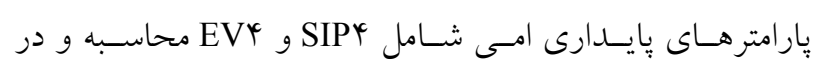

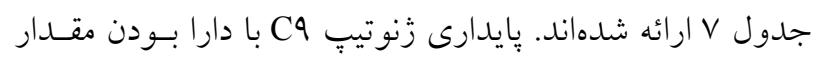

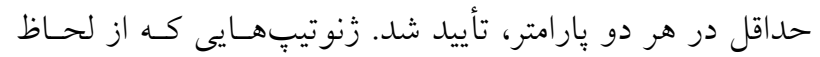

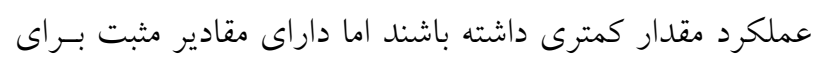

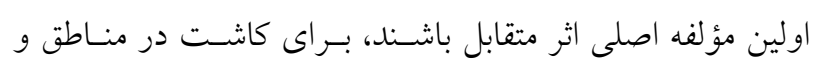

زنوتيب C9 (جيتى كاردينال) با بيشترين متوسط عملكرد و نيـز

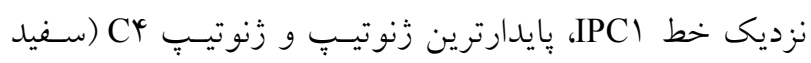

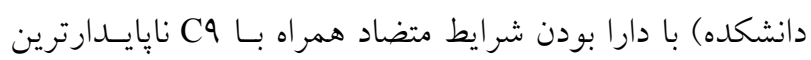

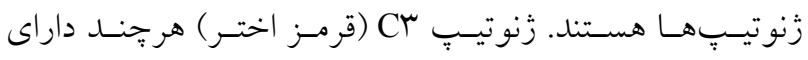

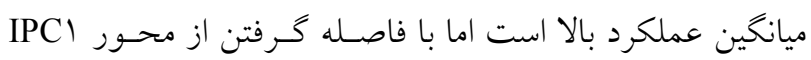
بهنوان رقم با سازكارى خصوصى معرفى مى مشود.

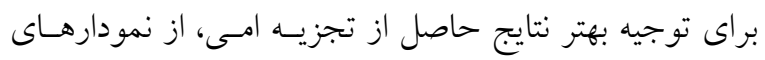

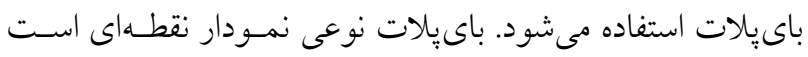

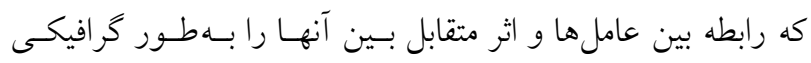

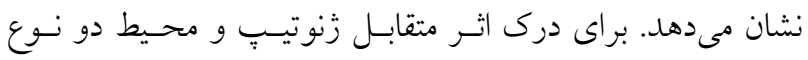

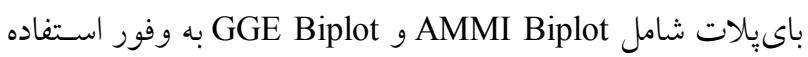

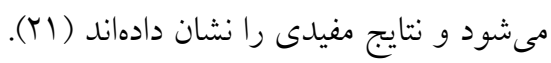

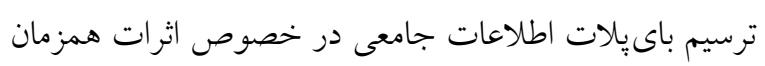

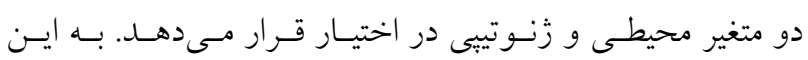

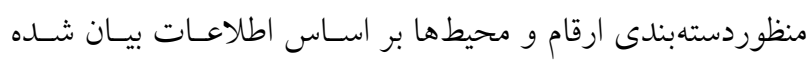

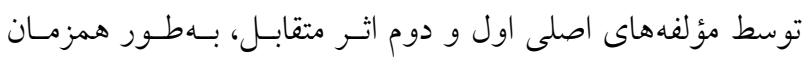

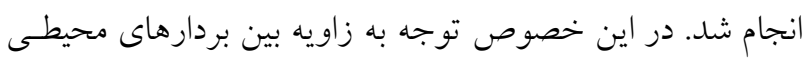

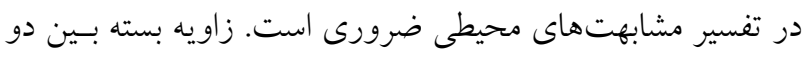




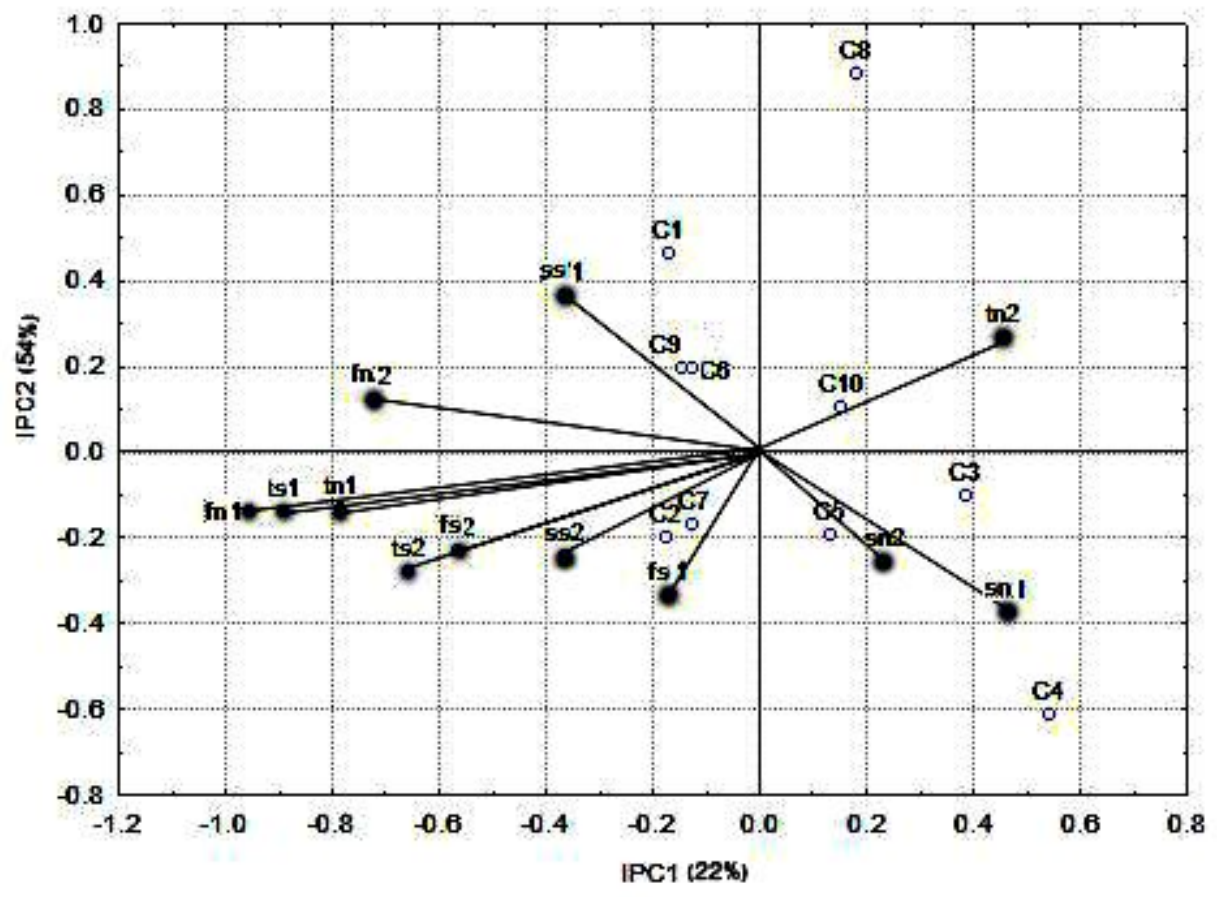

شكل r. نمودار باى بلات حاصل از ترسيم دو مؤلفه اول تجزيه AMMI

جدول V. آماره هاى بايدارى مدل AMMI F براى زنوتيب هاى لوبيا

\begin{tabular}{|c|c|c|}
\hline $\mathrm{EV}_{\digamma}$ & $\mathrm{SIP}_{\uparrow}$ & زُنوتيِ \\
\hline.$\% 1 V$ & $1 / 94$ & $\mathrm{Cl}$ \\
\hline $0 / 01 \mathrm{~V}$ & $1 / 4 \wedge$ & $\mathrm{Cr}$ \\
\hline$\circ \% \circ \mathrm{V}$ & $0 / 99$ & $\mathrm{Cr}^{\mathrm{r}}$ \\
\hline 01011 & $1 / 91$ & $\mathrm{Cr}^{r}$ \\
\hline \%०० & $0 / 9 \mathrm{~V}$ & $\mathrm{CD}$ \\
\hline$\%$ \% ४ & $1 / r T$ & C\& \\
\hline 01009 & $0 / 9 \mathrm{~V}$ & $\mathrm{CV}$ \\
\hline$\% \Delta \Delta r$ & r & $\mathrm{CA}$ \\
\hline \%००Y & $0 / 90$ & $\mathrm{Ca}$ \\
\hline$\%$ \%O & $1 / 79$ & $\mathrm{Cl}$ 。 \\
\hline
\end{tabular}

تاريخهاى كاشت اول تقريباً مجاور هم قرار كرفتـهانــ و در

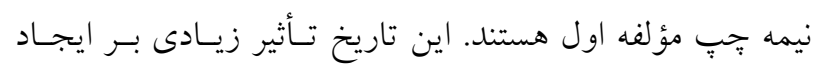

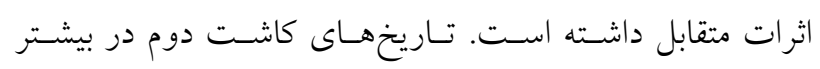

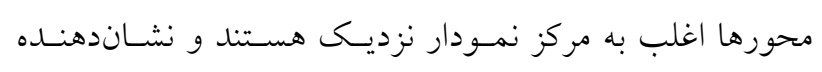

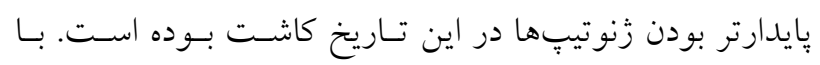

نواحى ضعيف مناسب هستند؛ به عبارتى با اين مناطق اثر متقابل

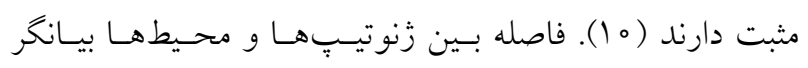

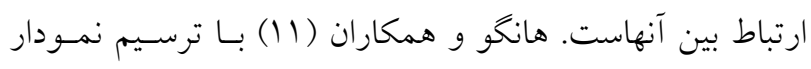

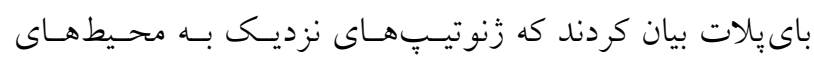

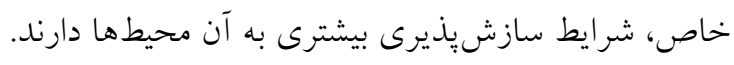


روش امى بهعنوان يك رقـم نإيايــار معرفى شــ، در ضـريب

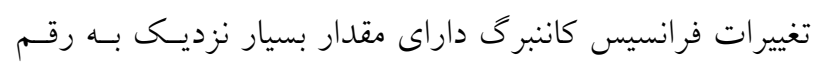

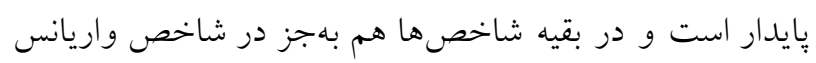

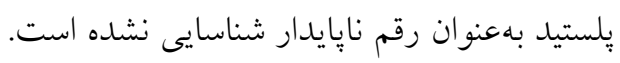

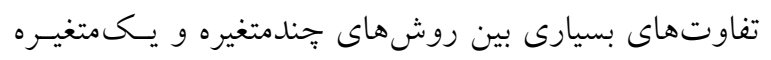

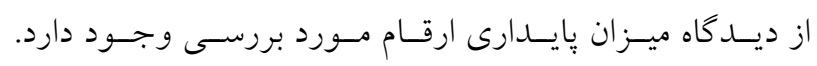

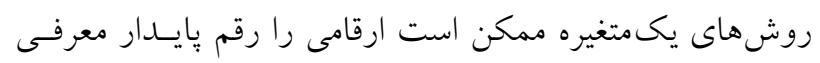

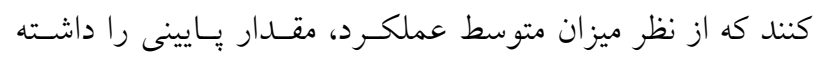

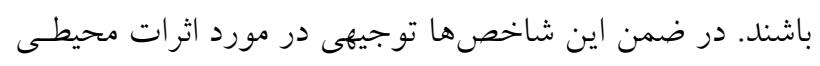

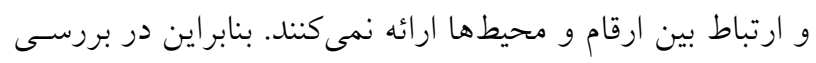

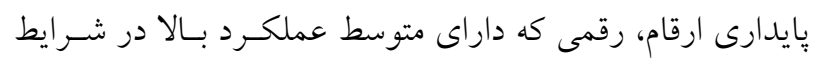

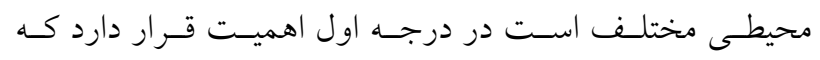
روش هاى يكمتغيره در شناسـايى ايسن ارقـام ناكارامــ هستـتند.

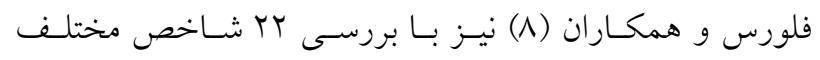

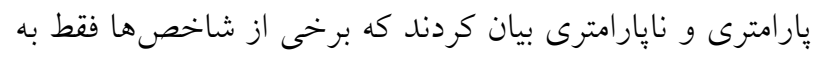

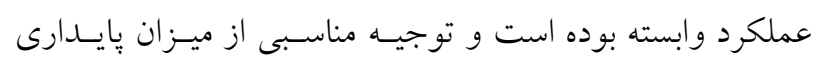

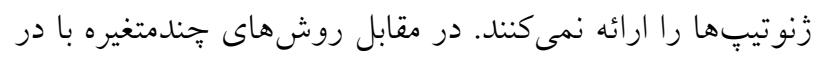

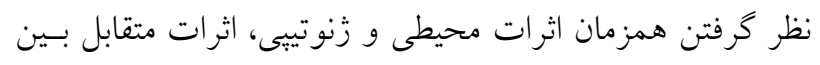

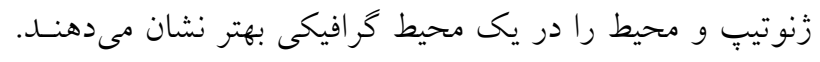

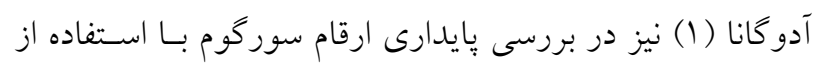

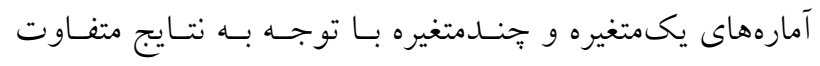

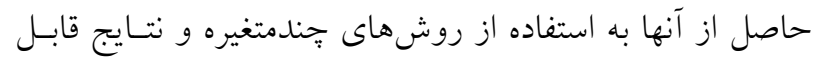

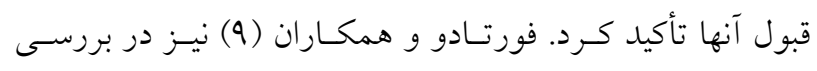

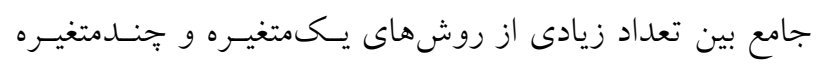

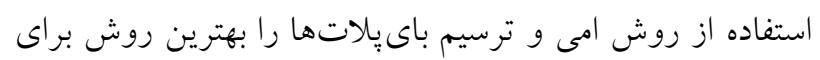
شناسايى ارقام بايدار معرفى كردند.

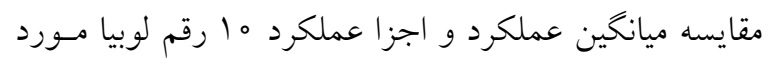

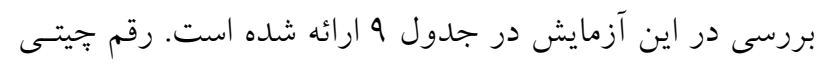

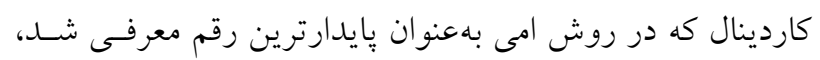

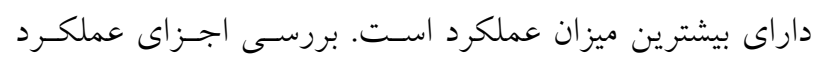

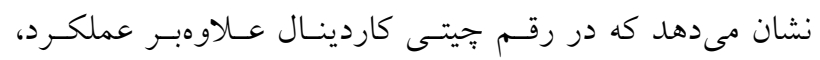

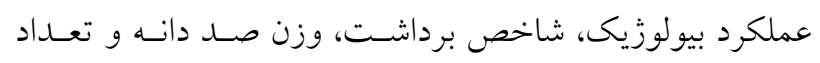

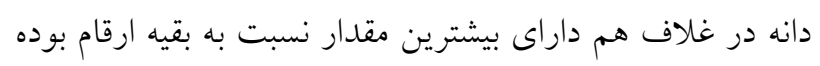

توجه به قراركيرى سال اول و دوم در مجـاورت هـم در اغلـب محيطها، مىتوان كفت تأثير سال بر ايجاد اثرات متقابـل نـاجيز درديز بوده است. از نظر شرايط تنش هم مى توان به اين نكته اشاره كـرد كـه

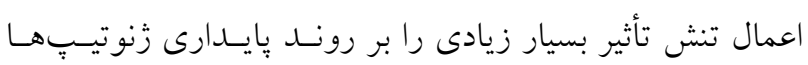

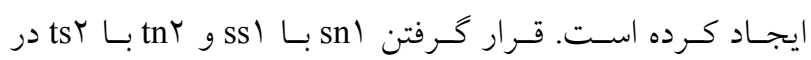
راستاى يك خط راست بيـانكر ايسن موضـوع اسـت. در بيشـتر محيطهاى ديخر نيز شرايط تنش و غير تنش بــا هـم زاويـهـ بــاز

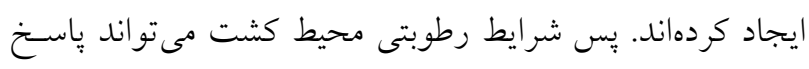

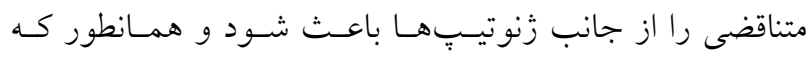

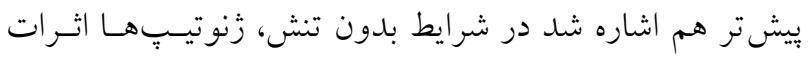

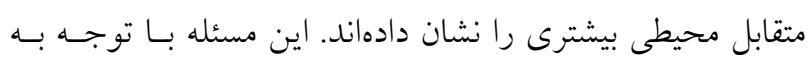

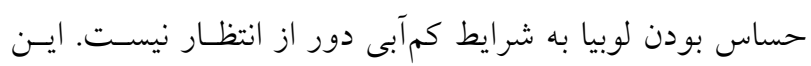

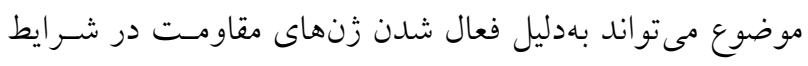

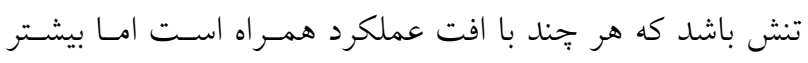

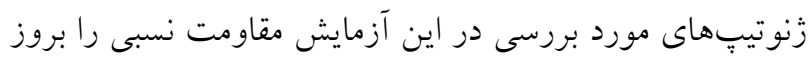

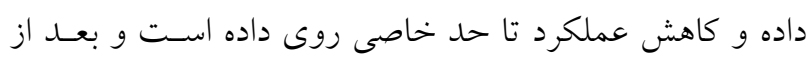
آن نسبت به افت عملكرد مقاومت بيشتر نشان دادهاند. تمسگن و همكاران (Y) با بر بوسى بايدارى ارقام سويا بيان

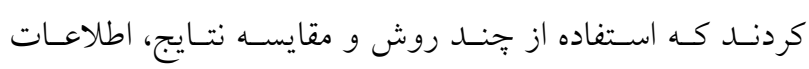

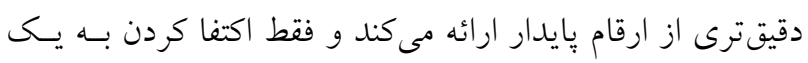

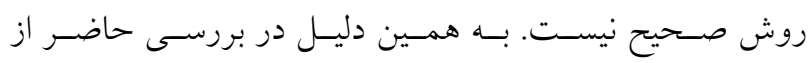
روشهاى آمارى يكمتغيره هم استفاده شد.

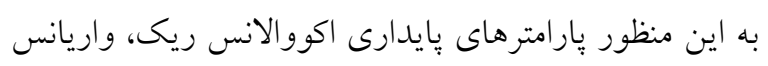

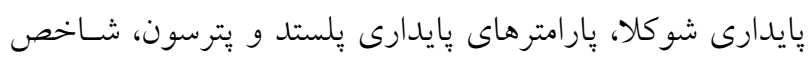

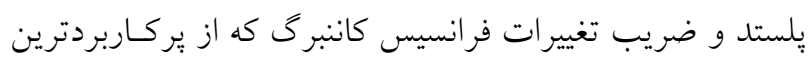

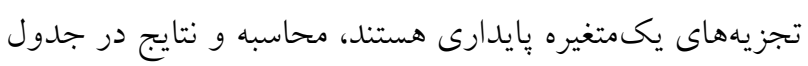

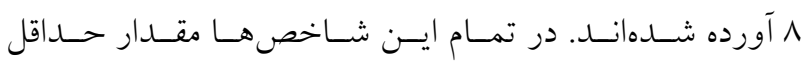

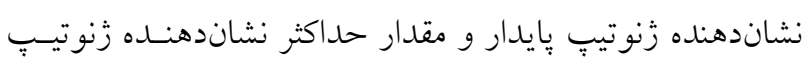

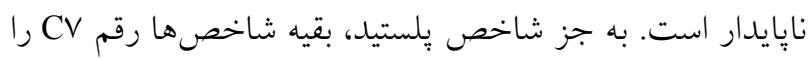

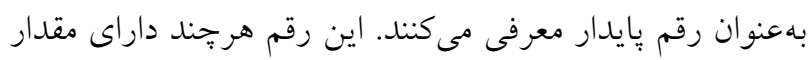

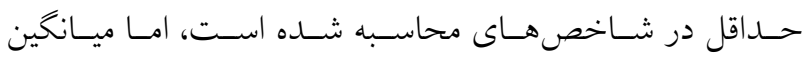

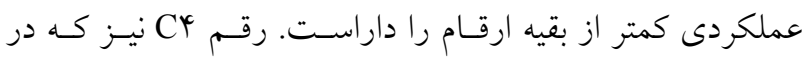


جدول ^^ نتايج حاصل از بارامترهاى بايدارى تكمتغيره در ه إقم لوبيا

\begin{tabular}{|c|c|c|c|c|c|c|}
\hline واريانس يلستد & و و و يترسون بِلستد & واريانس بايدارى شوكلا & اكووالانس & ضرانسيس كاننبرى & $\begin{array}{c}\text { ميانگين عملكرد } \\
\text { (kg/ha) }\end{array}$ & رَنوتيب \\
\hline$r .1$ & TQQ & rIV & 1019 & re/4 & TVQG & $\mathrm{Cl}$ \\
\hline M & 191 & $90 /$ & $4 \circ 4$ & $r T / 0$ & Tokr & $\mathrm{Cr}$ \\
\hline TrY & OVD & $9 T_{1}$ & 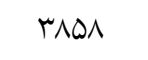 & $\Delta Q / \circ$ & $r \circ 9 \Lambda$ & $\mathrm{Cr}$ \\
\hline rYo & 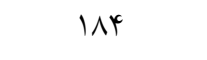 & $\varphi_{\Lambda}$ & MAT & $r \mu / 1$ & mra & $\mathrm{Cr}^{\mathrm{K}}$ \\
\hline rql & $r_{01}$ & rir & lrak & $\Delta G / Q$ & $19 Y 1$ & $\mathrm{C} \Delta$ \\
\hline rat & TM & TAY & ITVO & $0 . / 4$ & TrMO & $\mathrm{C} 9$ \\
\hline rTo & INT & ky & TTO & $\pi r / 9$ & YYOO & $\mathrm{CV}$ \\
\hline$r \circ \Delta$ & YYO & 1100 & 119 & TV/A & ras9 & $\mathrm{C} \wedge$ \\
\hline roo & r90 & ו וTr & loVr & $r_{1 / 4}$ & TrGO & $\mathrm{Ca}$ \\
\hline rQV & krv & 919 & relY & QY $N$ & TVVT & $\mathrm{Cl} \circ$ \\
\hline
\end{tabular}

جدول 9. مقايسه ميانگين عملكرد و اجزا عملكرد ه ا رقم لوبيا

\begin{tabular}{|c|c|c|c|c|c|c|c|}
\hline \multirow{2}{*}{ طول غلاف } & \multirow{2}{*}{ تعر غلاد دانه } & \multirow{2}{*}{ غلاف } & \multirow{2}{*}{ وزن صد دانه } & \multirow{2}{*}{ شاخص } & بيولوزيك عملكرد & عملكرد دانه & \multirow[t]{2}{*}{ رقم } \\
\hline & & & & & \multicolumn{2}{|c|}{ (كيلو گرم در هكتار) } & \\
\hline $9 / \Gamma^{\mathrm{cd}}$ & $\Delta / \Psi^{\mathrm{ab}}$ & $r Q / q a b$ & $r q / \Lambda^{c d}$ & $\circ / \Delta \mathrm{r}^{\mathrm{rab}}$ & $9 \circ 94 / c a b$ & TV৭\&/qabcd & قرمز كلى (Cl) \\
\hline $10 / \kappa^{b}$ & $\Delta / \omega^{a}$ & $\mid V / q^{c}$ & $r \varphi / q^{c d}$ & $\odot / 0$ ab & FITN/qcd & rorr/ $N^{\mathrm{cd}}$ & قرمز صياد (Cr) \\
\hline $11 / 9^{a}$ & $r / q^{b c d}$ & $19 / \wedge^{c}$ & $\Delta 1 / T^{a b}$ & $\circ / D \circ a b c$ & $\Delta \vee \backslash Q / \overline{G a b c}$ & $r \circ q \Lambda / Y^{a b}$ & قرمز اختر (Cr) \\
\hline $10 / 9 \mathrm{~b}$ & $\varphi / 4 d$ & $r q / \pi^{\mathrm{ab}}$ & $\mu \varphi / \mu^{b c}$ & $\circ / 4 \vee b c$ & OrMN/qcde & $r$ rrq/4cd & سفيد دانشكده (CY) \\
\hline $9 / \pi^{\mathrm{cd}}$ & $r / q^{d}$ & $r q / \wedge^{a b}$ & $r q /\left.\right|^{c d}$ & $\circ / r q c$ & YOYA/qbcd & $19 Y N / V^{d}$ & سفيد CD) Jules) \\
\hline$\Lambda / Q^{d}$ & $\varphi / \sigma^{d}$ & $r / / b^{b c}$ & $r Y / T^{d}$ & $\circ /\left.\Delta\right|^{\mathrm{abc}}$ & $\uparrow \diamond \wedge \circ \%$ bcd & $r M M_{0} / \varphi^{\mathrm{cd}}$ & سفيد دهقان (C9) \\
\hline $9 / 9 \mathrm{bc}$ & $Y / \sigma^{d}$ & $r M / \mu^{b c}$ & $r \Delta / \Delta^{b c}$ & $0 / 9 Y^{a}$ & $r 99 r / T^{d}$ & $Y Y_{0} \circ / r^{b c d}$ & سفيد CV) Emerson \\
\hline $10 / \mathrm{rbc}^{\mathrm{bc}}$ & $Q / \mathrm{oabc}$ & $r Q / 9 \mathrm{ab}$ & $\uparrow q / q^{b}$ & $\circ / 4 V^{b c}$ & $V 011 / /^{a}$ & $r 999 / 9 \mathrm{abcd}$ & جيتى (C^) CranVQ) \\
\hline $10 / 9^{b}$ & $\mathrm{Q} / /^{\mathrm{ab}}$ & $r / / \Delta^{b c}$ & Q1/ $\mathrm{Q}^{\mathrm{ab}}$ & $\circ / \Delta \wedge^{\mathrm{ab}}$ & $\Delta \Delta 99 / N^{\mathrm{abcd}}$ & $M Y G D / Y^{a}$ & جيتى كاردينال (C9) \\
\hline $10 / 1 \mathrm{bc}$ & $\varphi / q^{c d}$ & $r \& / q^{\mathrm{ab}}$ & $9 \circ / 0^{a}$ & $0 / 4$ \&bc & $\Delta D Y N / q_{\text {abcd }}$ & $T W V Y / r^{\mathrm{abccd}}$ & حيتى Mich MP (Cl () \\
\hline
\end{tabular}

اعداد داراى حداقل يكى حرف مشترى، تفاوت آمارى معنىدار در سطح احتمال ينج درصد ندارند.

كه نشاندهنده اهميت اين صفات در افزايش عملكرد و بايدارى نشاندهنده اين است كه اين رقم از نظر اين صـفات نيـز داراى

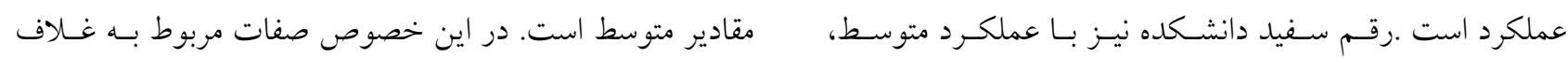

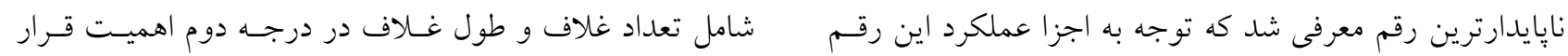




$$
\begin{aligned}
& \text { توصيه نمىشود. زنوتيب C9 (جيتى كاردينال) با بيشترين متوسط } \\
& \text { دارند. بهنظر مىرسد براى افزايش ميـزان پِيـــارى ارقـام لوبيـا، }
\end{aligned}
$$

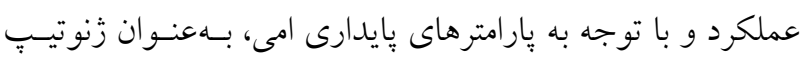

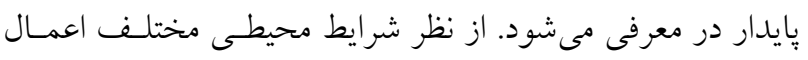

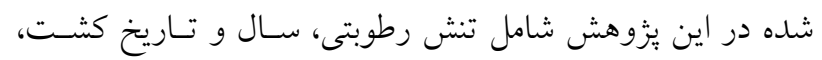

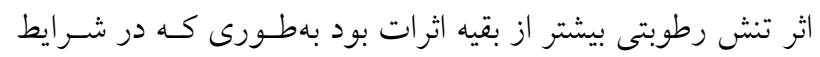

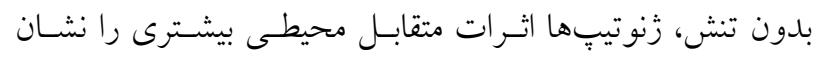

$$
\begin{aligned}
& \text { دادند. بررسى صفات مربوط بـهـ اجـزا عملكـرد در زنوتيـٍِهـاى }
\end{aligned}
$$

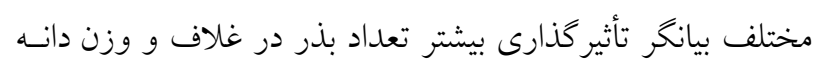

$$
\begin{aligned}
& \text { بر عملكرد است. بنابر اين در بهنز ادى لوبيا بـهمنظـور توليـــ ارقـام } \\
& \text { يايدار توجه به اين دو صفت داراى اهميت است. }
\end{aligned}
$$

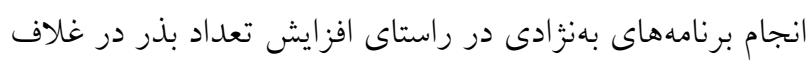

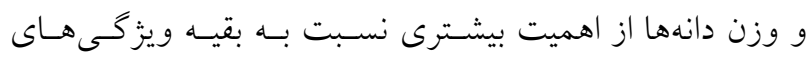

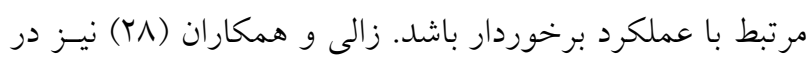

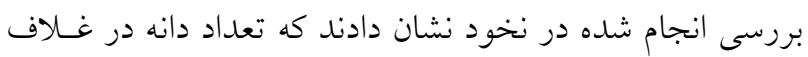

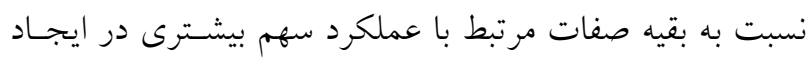

$$
\begin{aligned}
& \text { اثر متقابل زنوتيٍ و محيط دارد. }
\end{aligned}
$$

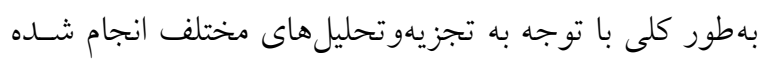

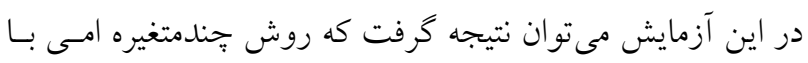

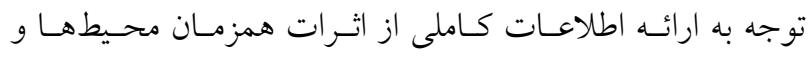

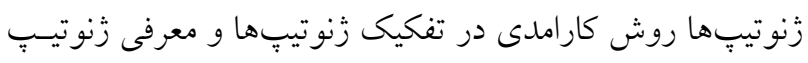

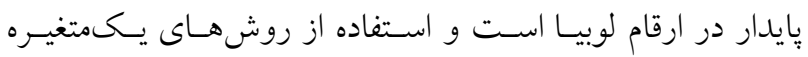

\section{منابع مورد استفاده}

1. Adugna, A. 2008. Assessment of yield stability in sorghum using univariate and multivariate statistical approaches. Hereditas 145(1): 28-37.

2. Azizi, A. H., S. Sardouie-Nasab, G. Mohammadi-Nejad, B. Nakhoda, M. Mardi, S. M. T. Tabatabaie, A. Amini and E. Majidi-Heravan. 2017. Estimation of genotype by environment interaction and pattern analysis of genotype in varied bread wheat lines under salinity stress condition. Journal of Crop Breeding 8(19): 80-92. (In Farsi).

3. Beebe, S. E., I. M. Rao, M. W. Blair and J. A. Acosta-Gallegos. 2013. Phenotyping common beans for adaptation to drought. Frontiers in Physiology 4(35): 1-20 .

4. Castro-Guerrero, N. A., M. C. Isidra-Arellano, D. G. Mendoza-Cozatl and O. Valdés-López. 2016. Common bean: A legume model on the rise for unraveling responses and adaptations to iron, zinc, and phosphate deficiencies. Frontiers in Plant Science 7: 1-7.

5. De Ron, A. M., R. Papa, E. Bitocchi, A. M. González, D. G. Debouck, M. A. Brick, D. Fourie, F. Marsolais, J. Beaver, V. Geffroy, P. McClean, M. Santalla, R. Lozano, F. J. Yuste-Lisbona and P. A. Casquero 2015. Common bean. pp. 1-36, In: A. M. De Ron (Eds). Grain legumes. Springer, New York, US.

6. FAO. 2006. FAO statistical databases. Available online at: http://faostat.fao.org. Accessed 20 July 2018.

7. Farshadfar, E. 1997. Application of biometrical genetics in plant breeding. Taghbostan Publication, Iran .

8. Flores, F., M. T. Moreno and J. I. Cubero. 1998. A comparison of univariate and multivariate methods to analyze g×e interaction. Field Crops Research 56(3): 271-286.

9. Furtado Ferreira, D., C. Garcia Borges Demétrio, B. F. John Manly, A. de Almeida Machado and R. Vencovsky. 2006. Statistical models in agriculture: Biometrical methods for evaluating phenotypic stability in plant breeding. Cerne Lavras 12(4): 373-388 .

10. Hanamaratti, N. G., P. M. Salimth., C. H. M. Vijayakumar, R. L. Ravikumar, S. T. Kajjidoni and M. B. Chetti. 2009. Genotype stability of superior near isogenic introgression lines for productivity in upland rice. Karnataka Journal of Agriculture Science 22: 736-740 .

11. Hongyu, K., M. García-Peña, D. Araújo Lúcio Borges and D. Santos Dias Carlos Tadeu. 2014. Statistical analysis of yield trials by ammi analysis of genotype ×environment interaction. Biometrical Letters 51(2): 89-102 .

12. Kang, M. S., V. T. Prabhakaran and R. B. Mehra 2004. Genotype-by-environment interaction in crop improvement. pp. 535-572, In: H. K. Jain and M. C. Kharkwal (Eds). Plant breeding: Mendelian to molecular approaches. Springer Netherlands, Dordrecht.

13. Kanouni, H., Y. Farayedi, S. H. Sabaghpour and A. Saeid. 2017. Assessment of genotype $\times$ environment interaction effect on seed yield of chickpea (Cicer arietinum L.) lines under rainfed winter planting conditions. Iranian Journal of Crop Sciences 18(1): 63-75. (In Farsi).

14. Kelly, J. D., K. A. Schneider and J. M. Kolkman 1999. Breeding to improve yield. pp. 185-222, In: S. P. Singh 
(Eds). Common Bean Improvement in the Twenty-First Century. Springer Netherlands, Dordrecht.

15. Kooshki, M. H., M. Ghaedrahmati, F. Salehi, H. R. Dorri, S. S. Shobeiri and M. B. K. Benam. 2017. Study of genotype $\times$ environment interaction effect on seed yield of red bean (Phaseolus vulgaris L.) genotypes using ammi method. Iranian Journal of Crop Sciences 19(1): 26-39. (In Farsi).

16. Malik, W. A., S. Hadasch, J. Forkman and H. P. Piepho. 2018. Nonparametric resampling methods for testing multiplicative terms in ammi and gge models for multienvironment trials. Crop Science 58(2): 752-761 .

17. Mohammadi, M., P. Sharifi and R. Karimizadeh. 2016. Stability analysis of seed yield of safflower genotypes (Carthamus tinctorius L.). Journal of Crop Breeding 7(16): 104-114. (In Farsi).

18. Mohammadi, R., M. Armion, E. Zadhasan, M. M. Ahmadi and A. Amri. 2017. The use of ammi model for interpreting genotype $\times$ environment interaction in durum wheat. Experimental Agriculture 1-14 .

19. Myers, J. R. and K. K. 2017. Common bean: Economic importance and relevance to biological science research. pp. 1-20, In: M. P. D. L. Vega, M. Santalla and F. Marsolais (Eds). The Common Bean Genome. Compendium of Plant Genomes. Springer International Publishing Cham.

20. Ponnuswamy, R., A. Rathore, A. Vemula, R. R. Das, A. K. Singh, D. Balakrishnan, H. S. Arremsetty, R. B. Vemuri and T. Ram. 2018. Analysis of multi-location data of hybrid rice trials reveals complex genotype by environment interaction. Cereal Research Communications 46(1): 146-157 .

21. Rakshit, S., K. N. Ganapathy, S. S. Gomashe, A. Rathore, R. B. Ghorade, M. V. N. Kumar, K. Ganesmurthy, S. K. Jain, M. Y. Kamtar, J. S. Sachan, S. S. Ambekar, B. R. Ranwa, D. G. Kanawade, M. Balusamy, D. Kadam, A. Sarkar, V. A. Tonapi and J. V. Patil. 2012. Gge biplot analysis to evaluate genotype, environment and their interactions in sorghum multi-location data. Euphytica 185(3): 465-479.

22. Safavi, M. and S. Bahraminejad. 2017. The evaluation of genotype $\times$ environment interactions for grain yield of oat genotypes using ammi model. Journal of Crop Breeding 9(22): 125-132. (In Farsi).

23. Sall, A. T., M. Cisse, H. Gueye, H. Kabbaj, I. Ndoye, A. Filali-Maltouf, B. Belkadi, M. El-Mourid, R. Ortiz and F. M. Bassi. 2018. Heat tolerance of durum wheat (Tritcum durum) elite germplasm tested along the senegal river. Journal of Agricultural Science 10(2): 217-233 .

24. Sharifi, P., H. Aminpanah, R. Erfani, A. Mohaddesi and A. Abbasian. 2017. Evaluation of genotype $\times$ environment interaction in rice based on ammi model in iran. Rice Science 24(3): 173-180 .

25. Shiri, M. R. and T. Bahrampour. 2015. Genotype $\times$ environment interaction analysis using gge biplot in grain maize (Zea mays L.) hybrids under different irrigation conditions. Cereal Research 5(1): 83-94. . (In Farsi).

26. Temesgen, T., G. Keneni, T. Sefera and M. Jarso. 2015. Yield stability and relationships among stability parameters in faba bean (Vicia faba L.) genotypes. The Crop Journal 3(3): 258-268 .

27. Zali, H., F. A. and S. H. Sabaghpour. 2011. Evaluation of stability of grain yield and contribution of the yield components in cheakpea genotypes under rainfed contribuation. Crop Production in Environmental Stress 2: 17-30. (In Farsi). 


\title{
Assessment of Yield Stability in Common Bean Cultivars Based on Univariate and Multivariate Methods
}

\author{
M. Rabiei ${ }^{*}$ and M. Khodambashi
}

(Received: November 10-2018; Accepted: February 23-2019)

\begin{abstract}
Stability and adaptability of ten common bean cultivars were studied in water stressed and normal conditions, three planting dates (including 5 May, 20 May and 5 June), and two years (2014 and 2016) in Shahrekord, Iran. Combined analysis of variance for yield indicated that the effect of genotype by environment interaction was significant; therefore, more accurate statistical analyses were required to evaluate yield stability of each cultivar. Stability analysis was performed using some univariate methods and a multivariate method (AMMI model). Comparison of univariate and multivariate stability parameters showed that AMMI model is more effective and practical than univariate methods. In AMMI model, graphical discrimination of the genotypes and the environments facilitated the identification of stable and high yielding genotypes. In this regard, Chiti cardinal genotype had high yield and wide adaptability to diverse environments. This genotype had the minimum amount of the first and the second interaction principal components scores (IPC1 and IPC2) in the AMMI model as well as the minimum value of AMMI stability parameters including EV4 and SIPC4; hence this genotype is introduced as a genotype having general stability. In contrast, genotype Akhtar had a high yield potential; however, in biplot graph this genotype was located close to IPC1 and away from IPC2, which implies that Akhtar has specific adaptability to some environments. Biplot graph also showed that among the different environments which were involved in this experiment, year had not fundamental effect on various performance of genotypes. In the second planting date, the genotypes performances were more consistent than the first planting date; moreover, the genotypes responses under moisture stressed conditions were different and unpredictable. In conclusion, sowing of Cardinal genotype in second planting date (20 May) under well-irrigated conditions is recommended for the Shahrekord in central west of Iran.
\end{abstract}

Keywords: AMMI, Biplot, Planting date, Moisture stress, Stability

1, 2. Assistant Professor and Professor, Respectively, Department of Agronomy and Plant Breeding, Faculty of Agriculture, Shahrekord University, Shahrekord, Iran.

*: Corresponding Author, Email: mrabiei@yandex.ru 